\title{
Evolution of Endoscopic Lesions in Steroid-Refractory Acute Severe Ulcerative Colitis Responding to Infliximab or Cyclosporine
}

\section{Laharie, David}

2021-06

Laharie , D , Bourreille , A , Branche , J , Allez , M , Bouhnik , Y, Filippi , J , Zerbib , F , Savoye , G, Vuitton , L , Moreau , J, Amiot , A , Beaugerie , L , Ricart , E , Dewit , O , Lopez-Sanroman , A , Fumery , M , Carbonnel , F , Buisson , A , Coffin , B , Roblin , X , van Assche , G , Esteve , M , Färkkilä, M , Gisbert , J P , Marteau , P, Nahon , S , de Vos , M , Peyrin-Biroulet , L \& Mary , J-Y 2021 , ' Evolution of Endoscopic Lesions in Steroid-Refractory Acute Severe Ulcerative Colitis Responding to Infliximab or Cyclosporine

' , Clinical Gastroenterology and Hepatology , vol. 19 , no. 6 , pp. 1180-+ . https://doi.org/10.1016/j.cgh.2020.08.001

http://hdl.handle.net/10138/332740

https://doi.org/10.1016/j.cgh.2020.08.001

cc_by

publishedVersion

Downloaded from Helda, University of Helsinki institutional repository.

This is an electronic reprint of the original article.

This reprint may differ from the original in pagination and typographic detail.

Please cite the original version. 


\title{
Evolution of Endoscopic Lesions in Steroid-Refractory Acute Severe Ulcerative Colitis Responding to Infliximab or Cyclosporine
}

\author{
David Laharie, ${ }^{*}$ Arnaud Bourreille, ${ }^{\ddagger}$ Julien Branche, ${ }^{\S}$ Matthieu Allez, \\ Yoram Bouhnik, " Jerome Filippi, " Frank Zerbib, ${ }^{*}$ Guillaume Savoye, ${ }^{*}$ \\ Lucine Vuitton, ${ }^{\neq \neq}$Jacques Moreau, ${ }^{\S \S}$ Aurelien Amiot, ${ }^{\prime \mid l}$ Laurent Beaugerie, , \\ Elena Ricart, ${ }^{\# \#}$ Olivier Dewit, ${ }^{\star \star \star}$ Antonio Lopez-Sanroman, ${ }^{\neq \neq \ddagger}$ Mathurin Fumery, ${ }^{\S \S \S}$

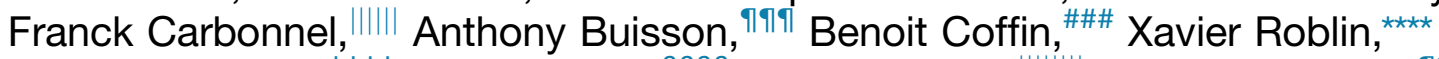 \\ Gert van Assche, ${ }^{\ddagger \neq \neq \neq}$ Maria Esteve, ${ }^{\S \S \S \S ~ M a r t t i ~ F a r k k i l a, ~|||||| \mid ~ J a v i e r ~ P . ~ G i s b e r t, ~}$ \\ Philippe Marteau, ${ }^{\# \# \# ~ S t e p h a n e ~ N a h o n, ~}{ }^{* \star k \star \star}$ Martine de Vos, ${ }^{\ddagger \neq \neq \neq \neq}$ \\ Laurent Peyrin-Biroulet, ${ }^{\S \S \S \S}$ and Jean-Yves Mary ${ }^{||||||||||}$
}

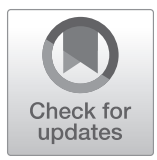

*INSERM CIC 1401, Service d'hépato-gastroentérologie et oncologie digestive, Centre Medico-chirurgical Magellan, Hôpital Haut-Lévêque, CHU de Bordeaux, Université de Bordeaux, Bordeaux, France; ' Institut des Maladies de l'Appareil Digestif, Hépato-Gastroentérologie, Hôtel-Dieu, CHU de Nantes, Nantes, France; §Service des maladies de l'appareil digestif-Endoscopie digestive, Hôpital Claude Huriez, CHRU de Lille, Lille, France; "Service d'Hépato-Gastroentérologie, Hôpital Saint-Louis, Assistance Publique-Hôpitaux de Paris, Université Paris VII, Paris, France; "Gastroentérologie, MICl et Assistance Nutritive, Hôpital Beaujon, Assistance Publique-Hôpitaux de Paris, Université Paris VII, Clichy, France; "Service de Gastroentérologie et Nutrition Clinique, Hôpital de l'Archet 2, CHU de Nice, Nice, France; **UMR 1073, Service de Gastroentérologie, Hôpital Charles Nicolle, CHU de Rouen, Normandie Université-Rouen, Rouen, France; ${ }^{\ddagger \ddagger}$ Service de

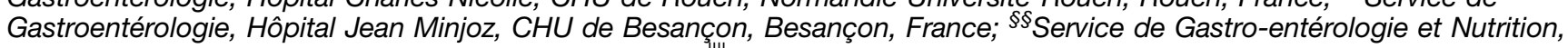
Hôpital Rangueil, CHU de Toulouse, Toulouse, France; "1Ill Service d'Hépato-gastroentérologie, Hôpital Henri Mondor, Assistance Publique-Hôpitaux de Paris, Université Créteil, Créteil, France; "in"Department of Gastroenterology, Institut Pierre Louis d'Epidémiologie et de Santé Publique, INSERM, Hôpital Saint-Antoine, Assistance Publique-Hôpitaux de Paris, Paris, France; \#\#Gastroenterology Department, Hospital Clínic, Augus Pi i Sunyer Biomedical Research Institute, Centro de Investigación Biomédica en Red de Enfermedades Hepáticas y Digestivas, Barcelona, Spain; **Service d'HépatoGastroentérologie, UCL Saint Luc, Brussels, Belgium; ${ }^{\ddagger \neq}$ Unidad de Ell / IBD Unit, Servicio de Gastroenterología y Hepatología, Hospital Ramón y Cajal, Madrid, Spain; §\$§ Peritox UMR I-01, Service d'Hépato-Gastroentérologie, CHU Amiens, Amiens, France; "IIIIIIService d'Hépato-Gastroentérologie, Hôpital Bicêtre, Assistance Publique-Hôpitaux de Paris, Université Paris Sud 11, Le Kremlin-Bicêtre, France; "179 INSERM U1071, M2iSH, USC-INRA 2018, 3iHP, Service d'Hépato-Gastroentérologie, CHU Clermont-Ferrand, Université Clermont Auvergne, Clermont-Ferrand, France; \#\#\#ôle Maladie Appareil Digestif, Service d'Hépato-Gastroentérologie, Hôpital Louis Mourier, Assistance Publique-Hôpitaux de Paris, Université Paris VII, Colombes, France; ${ }^{* * * *}$ Service de Gastro-entérologie et Hépatologie, Hôpital Nord, CHU de Saint-Etienne, Saint-Etienne, France; ${ }_{\ddagger \neq \neq \neq}$ Division of Gastroenterology and Hepatology, University Hospital Leuven, Leuven, Belgium; ${ }^{\$ \S \S D e p a r t m e n t ~ o f ~}$ Gastroenterology, Hospital Universitari Mútua de Terrassa, Centro de Investigación Biomédica en Red de Enfermedades Hepáticas y Digestivas, Terrassa, Spain; "IIIIIIIClinic of Gastroenterology, Helsinki University Central Hospital, Helsinki University,

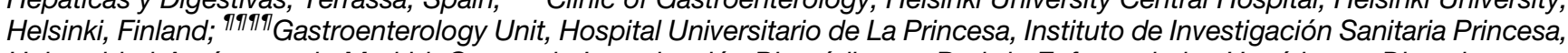
Universidad Autónoma de Madrid, Centro de Investigación Biomédica en Red de Enfermedades Hepáticas y Digestivas, Madrid, Spain; \#\#\#\# Service Hépato-gastroentérologie, Hôpital Tenon, Assistance Publique-Hôpitaux de Paris Sorbonne Université, Paris, France; ${ }^{* * * * S e r v i c e ~ d ' H e ́ p a t o-g a s t r o e n t e ́ r o l o g i e, ~ C H I ~ L e ~ R a i n c y ~ M o n t f e r m e i l, ~ M o n t f e r m e i l, ~ F r a n c e ; ~}$

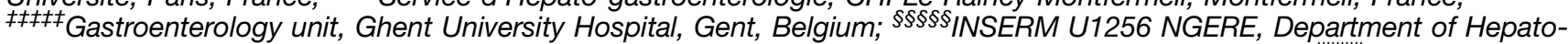

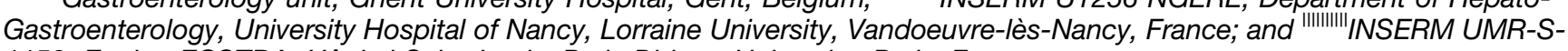
1153, Equipe ECSTRA, Hôpital Saint-Louis, Paris Diderot University, Paris, France

BACKGROUND/AIMS: $\quad$ Few data on the evolution of endoscopic findings are available in patients with acute severe ulcerative colitis (ASUC). The aim of this study was to describe this evolution in a prospective cohort.

METHODS:

Patients admitted for a steroid-refractory ASUC and included in a randomized trial comparing infliximab and cyclosporine were eligible if they achieved steroid-free clinical remission at day 98. Flexible sigmoidoscopies were performed at baseline, days 7,42 and 98 . Ulcerative colitis

Abbreviations used in this paper: IQR, interquartile range; UCEIS, Ulcerative Colitis Endoscopic Index of Severity.
(C) 2021 by the AGA Institute $1542-3565 / \$ 36.00$

https://doi.org/10.1016/j.cgh.2020.08.001 
RESULTS:

endoscopic index of severity (UCEIS) and its sub-scores - vascular pattern, bleeding and ulceration/erosion - were post-hoc calculated. Global endoscopic remission was defined by a UCEIS of 0 , and partial endoscopic remission by any UCEIS sub-score of 0 .

Among the 55 patients analyzed ( 29 infliximab and 26 cyclosporine), 49 (83\%) had UCEIS $\geq 6$ at baseline at baseline. Partial endoscopic remission rates were higher for bleeding than for vascular pattern and for ulcerations/erosions at day 7 (20\% vs. $4 \%$ and $5 \%(n=55) ; p=.004$ and $p=.04)$, for bleeding and ulceration/erosion than for vascular pattern at day $42[63 \%$ and $65 \%$ vs. 33\% $(n=54) ; p<.001$ for both] and at day 98 [78\% and $92 \%$ vs. 56\% $(n=50) ; p=.007$ and $p<.001]$. Global endoscopic remission rates at day 98 were higher in patients treated with infliximab than with cyclosporine [73\% vs. $25 \%(n=26$ and 24$) ; p<.001]$.

CONCLUSION:

In steroid-refractory ASUC patients responding to a second-line medical therapy, endoscopic remission process started with bleeding remission and was not achieved in half the patients at day 98 for vascular pattern. Infliximab provided a higher endoscopic remission rate than cyclosporine at day 98.

Keywords: ulcerative Colitis; Cyclosporine; Infliximab; Mucosal Healing; UCEIS.

$\mathrm{U}$ lcerative colitis is a chronic and disabling inflammatory bowel disease affecting the rectum and the colon, ${ }^{1}$ characterized by unpredictable inflammatory flares that can be in $25 \%$ of patients a lifethreatening severe attack. $^{2}$

Identification of patients having an acute severe ulcerative colitis is still based on the historical clinicobiological Truelove-Witts criteria. ${ }^{3,4}$ These patients should be emergently admitted in a dedicated unit to receive speed-acting parenteral drugs according to a standardized protocol with the aim to avoid salvage colectomy. ${ }^{4}$ The medical regimen starts with intravenous steroids, followed by infliximab or cyclosporine in case of failure. Despite an optimal management, even in experienced centers, acute severe ulcerative colitis death rate remains $1 \%$ in Western countries. ${ }^{5}$

The ultimate therapeutic objective in ulcerative colitis is to achieve sustained steroid-free clinical remission together with healing of endoscopic inflammatory lesions. ${ }^{4}$ Consequently, repeated endoscopic assessments have been implemented in practice to score the severity of endoscopic lesions to adjust the therapeutic strategy. The 2 more frequently used endoscopic ulcerative colitis scoring systems are the Mayo endoscopic subscore and the more recent Ulcerative Colitis Endoscopic Index of Severity (UCEIS) that has been built and validated on the most reproducible inflammatory items that are vascular pattern, bleeding, and erosions or ulcerations. ${ }^{6-9}$ Interestingly, UCEIS can be used for assessing patients with acute severe ulcerative colitis as shown by 2 retrospective cohorts. ${ }^{10,11}$

Few data are available on the evolution of acute severe ulcerative colitis endoscopic lesions. Therefore, the aim of the present study was to describe the evolution of endoscopic lesions in a prospective cohort of patients admitted for a steroid-refractory acute severe ulcerative colitis and included in the CYSIF trial, ${ }^{12}$ if they responded to a second-line medical therapy.

\section{Materials and Methods}

\section{Study Design and Patients}

The CYSIF trial was a European randomized, openlabel, controlled trial conducted in 23 French and Belgian GETAID (Groupe d'Etude sur les Affections Inflammatoires Digestives) and 6 European ECCO (European Crohn and Colitis Organisation) centers, comparing cyclosporine with infliximab in 115 patients admitted for steroid-refractory acute severe ulcerative colitis (EudraCT: 2006-005299-42; ClinicalTrials.gov: NCT00542152). Patients were included from June 2007 to August 2010. Briefly, eligible patients were adults having an acute severe ulcerative colitis defined by a Lichtiger score $>10$, who were refractory to at least 0.8 $\mathrm{mg} / \mathrm{kg} / \mathrm{d}$ of intravenous methylprednisolone or equivalent given for at least 5 days and who were naive for cyclosporine, infliximab, and thiopurine except if it was started $<4$ weeks before inclusion. Patients with indication for emergent colectomy or having proctitis, Crohn's disease, active infection, or usual contraindication to cyclosporine, infliximab, and thiopurine were excluded. Results of the initial study have been previously published in extenso, showing that treatment failure occurred in $60 \%$ patients given cyclosporine and $54 \%$ given infliximab. ${ }^{12}$

The institutional review board at each center approved the protocol, and all patients provided written informed consent.

For assessment of endoscopic disease activity, 4 flexible sigmoidoscopies planned in the study protocol were performed at baseline and at days 7, 42, and 98 in patients still in the study. Examinations were locally read and not recorded.

All patients enrolled into the CYSIF trial were included in the endoscopic post hoc analysis if they achieved steroid-free clinical remission at day 98, 
defined as total Mayo score at 2 or less with a Mayo endoscopic subscore at 1 or less, or if they had steroidfree Mayo endoscopic subscore at 2 and all other subscores at 1 or less at day 98 without new treatment initiated at day 98. Patients who experienced a relapse or any severe adverse event leading to treatment modification or interruption between day 7 and day 98 have been excluded.

\section{Endoscopic Findings}

For each endoscopic assessment, the following prespecified endoscopic lesions were recorded per segment (rectum and sigmoid colon) on a standardized form: erythema (absent, mild, moderate, frank), friability (absent, mild, moderate, marked), granularity (absent, present), erosion (absent, rare, intermediate, numerous), superficial ulceration (absent, rare, intermediate, numerous), and deep ulceration (absent, rare, intermediate, numerous), including well-like ulceration, mucosal detachment, and mucosal abrasion (absent, present), pseudopolyp (absent, present). The Mayo endoscopic subscore was reported from the standardized form. As UCEIS has been available since 2012, the total score and its subscores-vascular pattern, bleeding, and erosion/ulceration-were post hoc calculated in each segment from endoscopic reports as follows: vascular pattern was scored 0 when erythema was normal, 1 when it was mild, and 2 when it was moderate or frank; bleeding was scored as friability; erosions or ulcerations was scored 0 when erosion and ulceration were absent, 1 in presence of erosion but no ulceration, 2 in presence of superficial ulceration but not deep ulceration, and 3 in presence of deep ulceration. Global UCEIS and vascular pattern, bleeding, and erosions or ulcerations subscores were calculated for the whole examination as maximal values across rectum and sigmoid segments.

Global endoscopic remission was defined as UCEIS at 0 and partial endoscopic remission as vascular pattern subscore at 0 for vascular pattern, as bleeding subscore at 0 for bleeding, and as erosions or ulcerations subscore at 0 for ulceration or erosion.

\section{Objectives}

Objectives of the study were the following: (1) to describe the time course of Mayo endoscopic subscore, UCEIS, and UCEIS subscores globally and per treatment group; (2) to compare endoscopic remission between the 3 UCEIS subscores at each time point globally and per treatment group; (3) to compare the evolution of the UCEIS erosions or ulcerations subscore between patients having a subscore of 3 and those having a subscore of 2 at inclusion at each time point; (4) to compare global and partial endoscopic remission between rectum and sigmoid at each time point; and (5) to compare global and

\section{What You Need to Know}

\section{Background}

Endoscopic remission is a goal of treatment for ulcerative colitis. However, there have been few endoscopic analyses of patients admitted to the hospital with steroid-refractory acute severe ulcerative colitis.

\section{Findings}

Endoscopic remission of acute severe ulcerative colitis requires approximately 3 months. It starts with remission of bleeding, followed by healing of ulcerations and erosions, and then by restoration of the vascular pattern. A higher proportion of patients who received second-line therapy with infliximab achieved endoscopic remission than with cyclosporine.

\section{Implications for patient care}

Patients should not be assessed too early by flexible sigmoidoscopy-many features of acute severe ulcerative colitis require 3 months to heal. Infliximab provides a higher endoscopic remission rate than cyclosporine at 3 months.

partial endoscopic remission between patients treated with infliximab and those receiving cyclosporine and at each time point.

\section{Statistics}

Patient characteristics were described as number and percentage and median (interquartile range [IQR]) for qualitative and quantitative items, respectively. To describe the Mayo endoscopic subscore, UCEIS, and UCEIS subscores, number, mean $\pm \mathrm{SD}$, and proportions of each subscore value were used because median (IQR) was not enough informative due to too numerous ties. Partial endoscopic remission rates were compared between UCEIS subscores at each time point through paired chisquare tests. Global and partial endoscopic remission rates were compared similarly between rectum and sigmoid segments. UCEIS and UCEIS subscores were compared at each time point between both treatment groups, as endoscopic remission rates through chi-square test or as absolute levels through Mann-Whitney test.

According to the numerous tests performed, significance was achieved for a $P$ value $<.005$.

\section{Results}

\section{Study Population}

From the 115 patients randomized in the CYSIF trial, 55 have been included in the present endoscopic analysis (29 received infliximab and 26 cyclosporine) because 
Table 1. Main Patients' Characteristics and Endoscopic Findings at Baseline

\begin{tabular}{|c|c|c|c|}
\hline Characteristic & All $(\mathrm{N}=55)$ & Infliximab $(n=29)$ & Cyclosporine $(n=26)$ \\
\hline Female & $30(55)$ & $15(52)$ & $15(58)$ \\
\hline Age, y & $35(27-48)$ & $33(26-50)$ & $37(27-45)$ \\
\hline Disease duration, y & $2.1(0.2-7.0)$ & $1.5(0.2-4.9)$ & $2.8(0.6-7.8)$ \\
\hline Disease location E3 & $34(62)$ & $18(62)$ & $16(62)$ \\
\hline $\begin{array}{l}\text { Lichtiger score } \\
\quad 11 \\
12-13 \\
\geq 14\end{array}$ & $\begin{array}{l}12(11-13) \\
21(38) \\
22(40) \\
12(22)\end{array}$ & $\begin{array}{c}12(12-14) \\
6(21) \\
13(45) \\
10(34)\end{array}$ & $\begin{array}{c}11(11-13)^{a} \\
15(58) \\
9(35)^{a} \\
2(8)\end{array}$ \\
\hline Hemoglobin, g/dL & $10.4(9.2-11.8)$ & $11.4(9.5-12.1)^{b}$ & $9.7(8.9-10.7)^{c}$ \\
\hline $\mathrm{CRP}, \mathrm{mg} / \mathrm{L}$ & $41(24-70)$ & $46(31-73)$ & $28(18-58)^{c}$ \\
\hline Albumin, g/L & $28(23-31)$ & $24(22-30)^{d}$ & $28(27-31)$ \\
\hline Mayo endoscopic subscore & $3.0 \pm 0.1$ & $3.0 \pm 0.2$ & $3.0 \pm 0.0$ \\
\hline Mayo endoscopic subscore 3 & $53(96)$ & $29(100)$ & $24(92)$ \\
\hline UCEIS & $7.1 \pm 1.2$ & $7.0 \pm 1.1$ & $7.1 \pm 1.3$ \\
\hline $\begin{array}{l}\text { Vascular pattern UCEIS subsc } \\
\text { Mean } \pm \mathrm{SD} \\
\text { Subscores } 0 / 1 / 2\end{array}$ & $\begin{array}{c}2.0 \pm 0.0 \\
0 / 0 / 55\end{array}$ & $\begin{array}{c}2.0 \pm 0.0 \\
0 / 0 / 29\end{array}$ & $\begin{array}{c}2.0 \pm 0.0 \\
0 / 0 / 26\end{array}$ \\
\hline $\begin{array}{l}\text { Bleeding UCEIS subscore } \\
\text { Mean } \pm \text { SD } \\
\text { Subscores } 0 / 1 / 2 / 3\end{array}$ & $\begin{array}{l}2.3 \pm 0.9 \\
2 / 12 / 9 / 32\end{array}$ & $\begin{array}{c}2.2 \pm 1.0 \\
1 / 8 / 3 / 17\end{array}$ & $\begin{array}{c}2.3 \pm 0.9 \\
1 / 4 / 6 / 15\end{array}$ \\
\hline $\begin{array}{l}\text { Erosion/ulceration UCEIS subs } \\
\text { Mean } \pm \text { SD } \\
\text { Subscores } 0 / 1 / 2 / 3\end{array}$ & $\begin{array}{c}2.8 \pm 0.5 \\
0 / 2 / 9 / 44\end{array}$ & $\begin{array}{c}2.8 \pm 0.4 \\
0 / 0 / 6 / 23\end{array}$ & $\begin{array}{c}2.7 \pm 0.6 \\
0 / 2 / 3 / 21\end{array}$ \\
\hline
\end{tabular}

Values are $\mathrm{n}(\%)$, median (interquartile range), or mean $\pm \mathrm{SD}$, unless otherwise indicated.

Ulcerative colitis location according to the Montreal classification $(E 1: n=0)$.

CRP, C-reactive protein; UCEIS, Ulcerative Colitis Endoscopic Index of Severity.

${ }^{a} P<.01$.

${ }^{b} \mathrm{n}=28$.

${ }^{c} P<.05$.

${ }^{d} \mathrm{n}=27$.

they achieved steroid-free clinical remission at day 98 . Characteristics of these 55 patients were similar regarding age, sex, disease extension, median Lichtiger score, and median C-reactive protein level with those of the 60 randomized patients who were excluded from the present analysis.

Main patients' characteristics and endoscopic findings at baseline are presented per treatment arm in Table 1 . Briefly, 30 (55\%) were women with a median age of 35 (IQR, 27-48) years and a median disease duration since diagnosis of 2.1 (IQR, 0.2-7.0) years; 14 (25\%) patients were admitted for first attack of ulcerative colitis. At inclusion, patients had received intravenous steroids during 8 (IQR, 6-9) days; they had median Lichtiger score of 12 (IQR, 11-13).

Regarding endoscopic findings at baseline, all except 2 patients had Mayo endoscopic subscore of 3 and 49 (89\%) patients had UCEIS of 6 or more. Regarding UCEIS subscores at baseline, $55(100 \%)$ patients had a vascular pattern subscore of 2, $41(75 \%)$ a bleeding subscore of $2-3$, and 53 $(96 \%)$ an erosions or ulcerations subscore of 2-3.

\section{Evolution of Endoscopic Lesions}

UCEIS and Mayo endoscopic subscores are described in Figure 1, with UCEIS subscores in figure 2.

In the whole cohort, endoscopic remission defined by UCEIS of 0 was achieved in $1(\mathrm{n}=55,2 \%)$ patient at day $7,13(\mathrm{n}=54,24 \%)$ at day 42 , and $25(\mathrm{n}=50,50 \%)$ at day 98. The endoscopic remission rate for vascular pattern was lower than the endoscopic remission rates for bleeding, but not for erosions or ulcerations, at day 7 (20\% and 5\%; $\mathrm{n}=55 ; P=.004$ and $P=1.00$, respectively). The endoscopic remission rate for vascular pattern was lower than the endoscopic remission rates for bleeding and for erosions or ulcerations at day 42 (62\% and 65\%; $\mathrm{n}=54 ; P<.001$ for both) and at day 98 (78\% and 92\%; $\mathrm{n}=50 ; P=.007$ and $P<.001$, respectively) (Figure 3). As described in Supplementary Figure 1, these results were mainly observed among cyclosporine treated patients, whereas the subscore remission rates appeared to evolve in a more parallel way in patients on infliximab. 


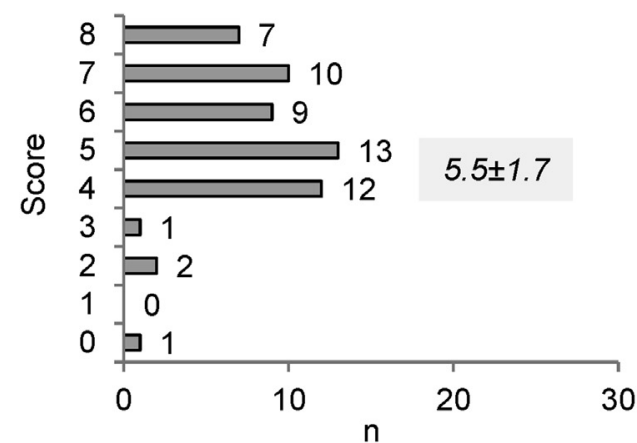

Day 7

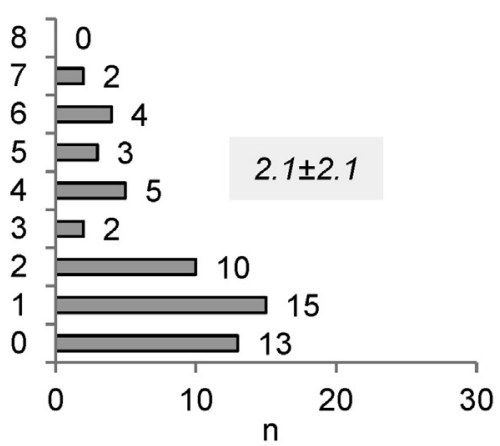

Day 42

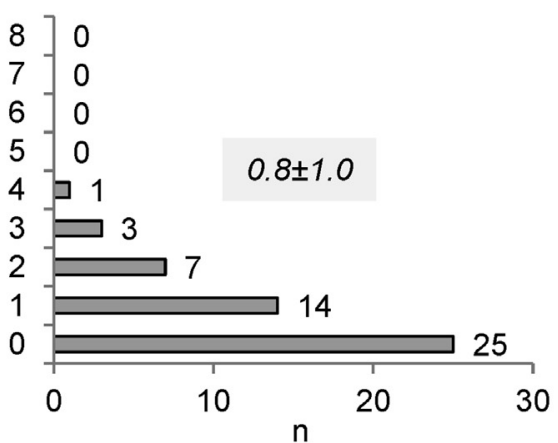

Day 98

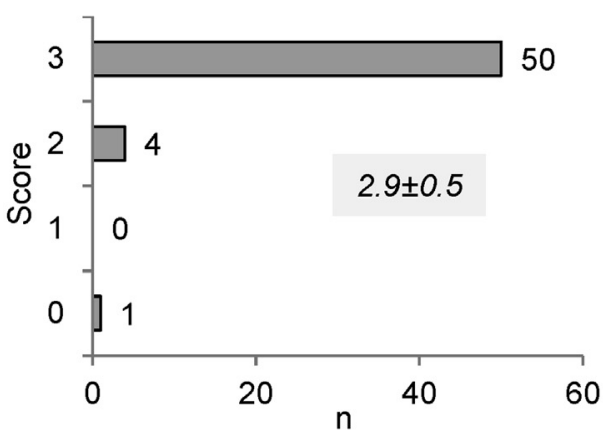

Day 7

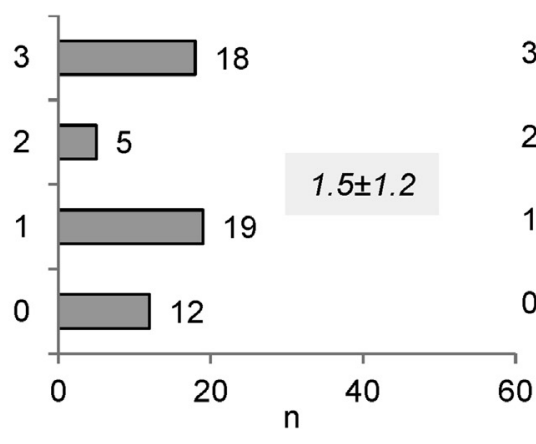

Day 42

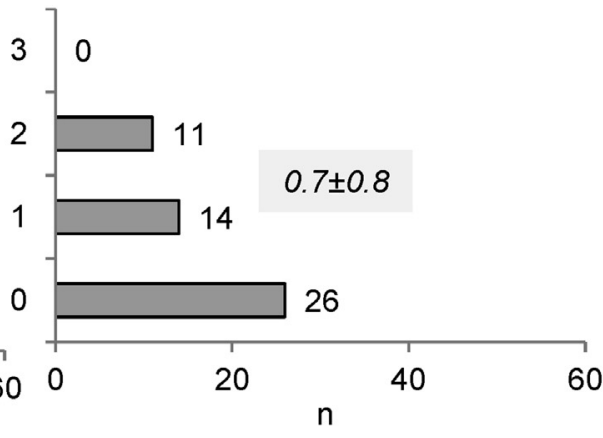

Day 98

Figure 1. Description of the UCEIS scores (top) and Mayo endoscopic subscores (bottom) at days 7 ( $n=55)$, $42(n=54)$, and $98(n=50)$ in patients admitted for a steroid-refractory acute severe ulcerative colitis who achieved clinical remission 98 days after receiving second-line medical therapy: number of patients for each level and mean $\pm \mathrm{SD}$.

When comparing patients having erosions or ulcerations subscore of 3 with patients having a erosions or ulcerations subscore of 2 at inclusion, proportions of patients achieving an erosions or ulcerations subscore of 0 were $0 \%$ and $22 \%(\mathrm{n}=44$ and 9$)$ at day $7(P=.03)$, $58 \%$ and $89 \%(\mathrm{n}=43$ and 9$)$ at day $42(P=.13)$, and $90 \%$ and $100 \%(\mathrm{n}=39$ and 9$)$ at day $98(P=1.00)$, respectively.

\section{Evolution of Endoscopic Lesions According to Bowel Segment}

There was no observed difference in endoscopic remission rates between sigmoid and rectum at each time point whatever the assessment used, UCEIS, or UCEIS subscores (Supplementary Table 1).

\section{Evolution of Endoscopic Lesions According to Medication}

Mayo endoscopic subscore, UCEIS, and UCEIS subscores are described according to treatment in Supplementary Figures 2 and 3.

Endoscopic remission rates with infliximab and cyclosporine were $3 \%$ and $0 \%(\mathrm{n}=29$ and $26 ; P=.34)$ at day $7,28 \%$ and $20 \%(\mathrm{n}=29$ and $25 ; P=.52)$ at day
42 and, $73 \%$ and $25 \%(\mathrm{n}=26$ and $24 ; P<.001)$ at day 98, respectively (Figure 4). Median UCEIS was significantly lower in patients treated with infliximab than in those who received cyclosporine only at day $98(P=$ $.002 ; P=.45$ at day 7 and $P=.64$ at day 42 ).

Regarding UCEIS subscores in patients treated by infliximab and cyclosporine, endoscopic remission rates at day 98 were $81 \%$ and $29 \%$ for vascular pattern $(P=$ $.002), 88 \%$ and $67 \%$ for bleeding $(P=.06), 88 \% \%$ and $96 \%$ for erosions or ulcerations $(P=.34)$, suggesting that the observed difference on UCEIS between infliximab- and cyclosporine-treated patients was mainly due to a difference in vascular pattern subscore (Supplementary Figure 4).

\section{Discussion}

In a prospective cohort of patients admitted for steroid-refractory acute severe ulcerative colitis responding to a second-line medical therapy, we observed that the process of endoscopic response in patients started from day 7 with absence of bleeding, and then followed by ulceration healing and by restoration of the vascular pattern, without discrepancies between sigmoid and rectum. We also observed that endoscopic remission rate at day 98 was higher 


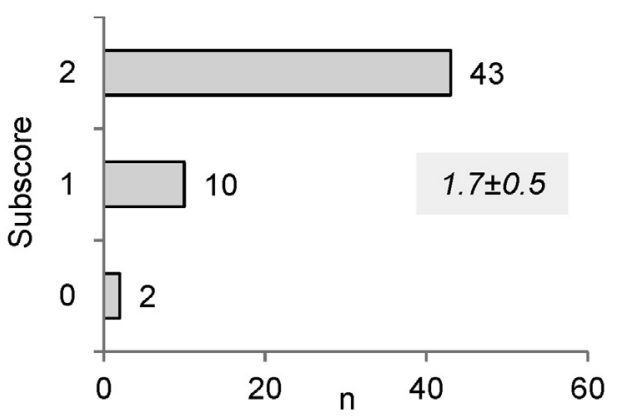

Day 7

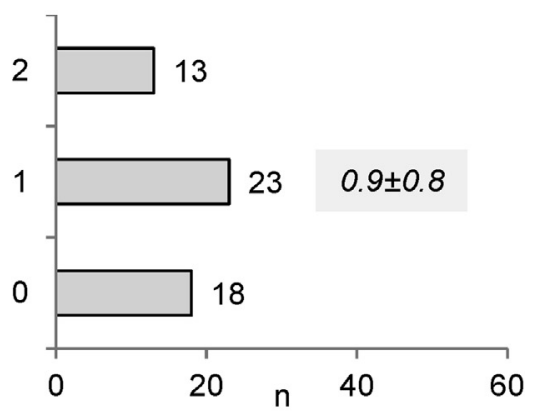

Day 42

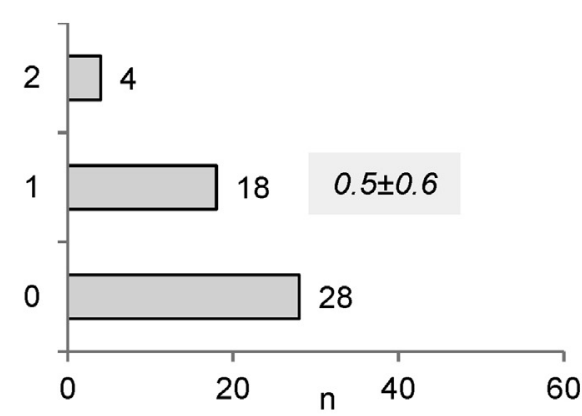

Day 98

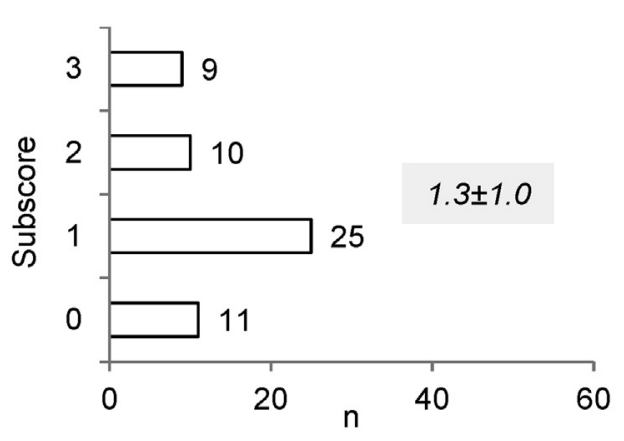

Day 7

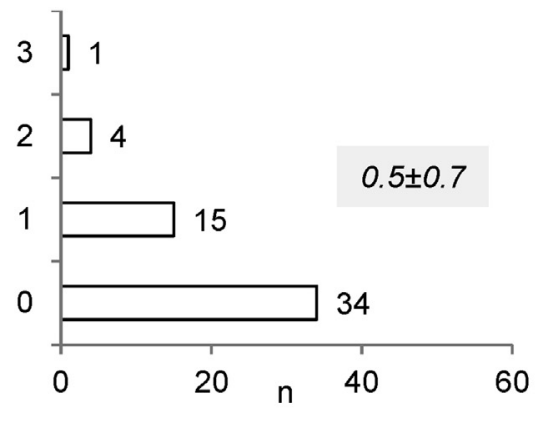

Day 42

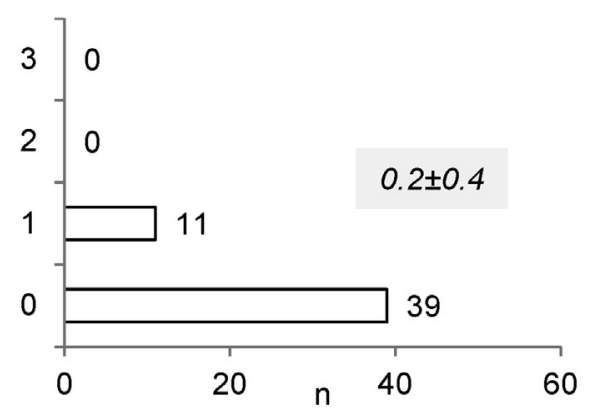

Day 98

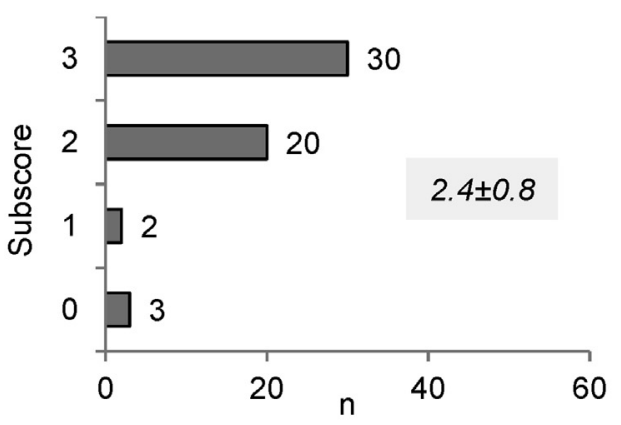

Day 7

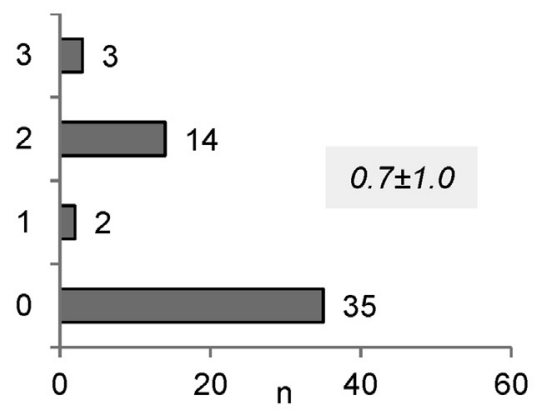

Day 42

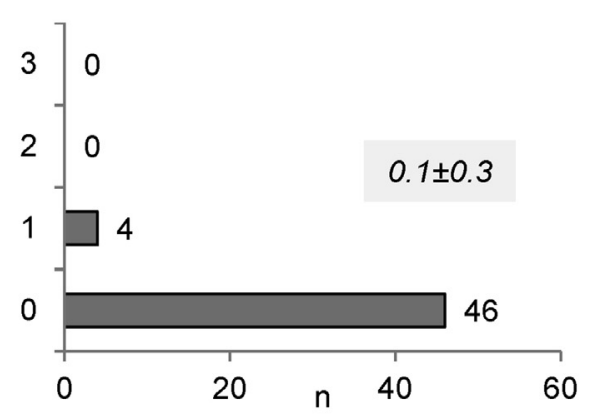

Day 98

\section{Vascular pattern}

\section{Bleeding}

\section{Erosion/ulceration}

Figure 2. Description of the UCEIS subscores at days $7(n=55), 42(n=54)$, and $98(n=50)$ in patients admitted for a steroidrefractory acute severe ulcerative colitis who achieved clinical remission 98 days after receiving second-line medical therapy: number of patients for each level and mean \pm SD.

in patients treated with infliximab than with cyclosporine.

Controlled trials assessing the efficacy of biologic agents in refractory ulcerative colitis, evaluated endoscopic remission - defined as Mayo endoscopic subscore of $0-1$-at the end of the induction period. ${ }^{13-19}$ However, data on the evolution of endoscopic lesions from baseline to this endpoint is scarce. Drug-related factors, such as its mode of action or speed of onset, and diseaserelated factors, like endoscopic severity at baseline and segmental location between colon and rectum, may influence the evolution of endoscopic healing in ulcerative colitis. This granularity of data cannot be captured by sequential fecal calprotectin measurements and requires repeated endoscopic assessments. We present here one of the first study conducted in ulcerative colitis that closely monitored endoscopic response by 4 flexible sigmoidoscopies within 14 weeks. The optimal time point for assessing mucosal healing in ulcerative colitis remains arbitrary, from 6 to 12 weeks in controlled trials, and depends on medication given. Our data suggest leaving sufficient time for healing to occur and to do not look at it too early in patients who started anti-tumor necrosis factor or cyclosporine.

We observed that bleeding and ulcerations improved within 6 weeks in two-thirds of patients, while the 


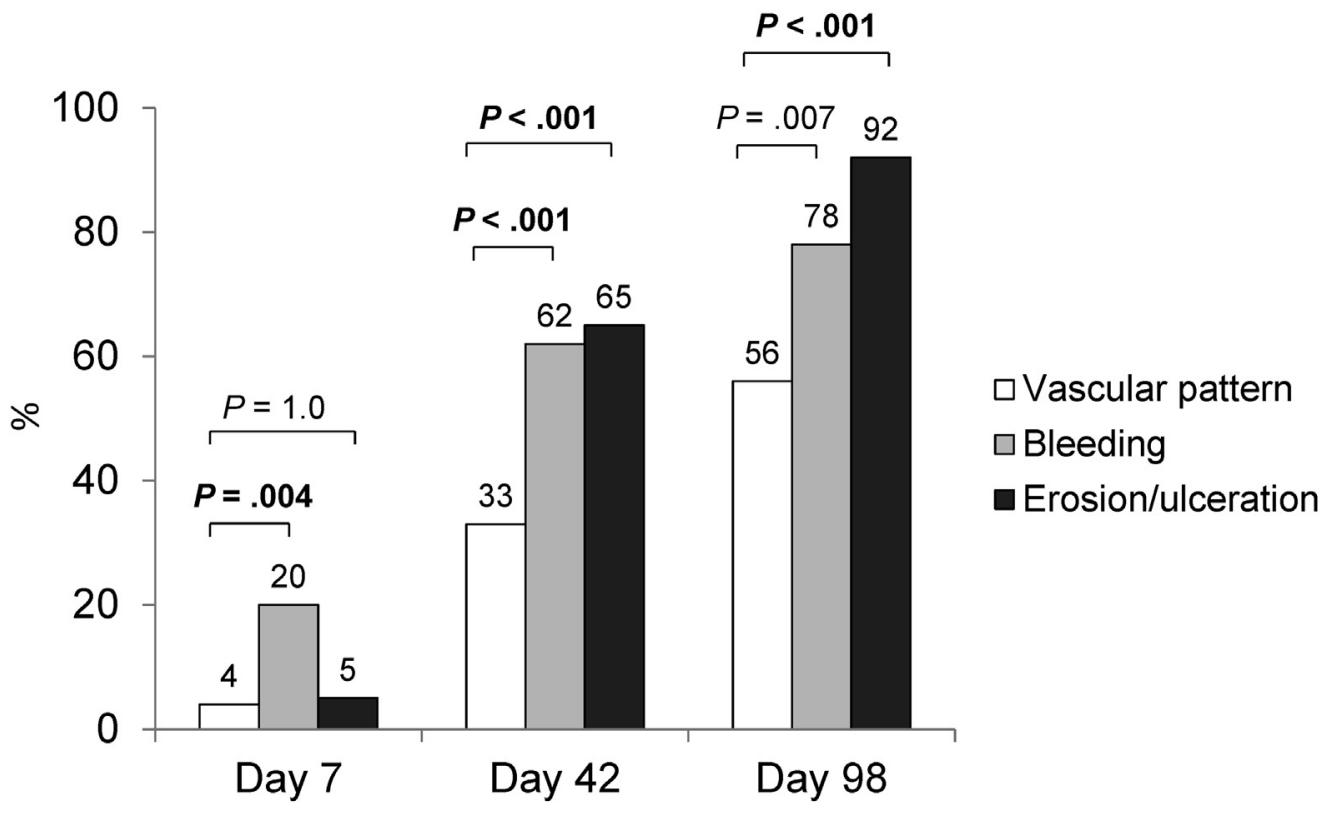

Figure 3. Evolution of vascular pattern, bleeding, and erosions or ulcerations UCEIS subscores at day $7(n=55), 42(n=54)$, and $98(n=50)$. Statistical significance was defined as $P<.005$ due to the numerous comparisons performed $(P$ value in bold).

recovery of normal vascular pattern took longer and was only achieved in half of patients at day 98. It could be speculated that histological remission would be the next step. Unfortunately, no biopsy samples were collected in our cohort.

Two randomized controlled trials have compared infliximab with cyclosporine in acute severe ulcerative colitis showing no difference on short and long-term outcomes between both drugs. ${ }^{12,20,21}$ However, in this ancillary study from the CYSIF trial, infliximab induced a significantly higher proportion of endoscopic remission (ie, Mayo endoscopic subscore or UCEIS 0) than did cyclosporine. This result was confirmed when comparing median UCEIS at day 98 while responders to infliximab had higher median Lichtiger score and C-reactive protein level at baseline than responders to cyclosporine. Such a finding may have an impact on subsequent disease course as several studies have shown that patients with a remnant mild endoscopic inflammation experience more relapse and surgery than those who achieved mucosal healing. $^{22-24}$ Indeed, $46 \%$ of patients initially treated with cyclosporine subsequently received infliximab during the first year of follow-up in our cohort. ${ }^{20}$

Beyond traditional features observed in active ulcerative colitis, acute severe attacks may be associated in $33 \%-72 \%$ to more severe endoscopic lesions, consisting of deep ulcerations, well-like ulcerations, or mucosal detachment mostly found in the rectum or the sigmoid colon. ${ }^{25-29}$ Conversely to prior endoscopic scores, severe endoscopic lesions have been implemented into the UCEIS corresponding to the erosions or ulcerations subscore at 3 defined as "deeper excavated defects in the mucosa, with a slightly raised edge."7 Some retrospectives series have observed an association between these lesions and higher colectomy rates or infliximab fecal excretion. $^{27,28,30}$ However, prospective studies have not
Figure 4. Rates of endoscopic remission (UCEIS at 0 ) in patients admitted for a steroid-refractory acute severe ulcerative colitis who achieved clinical remission 98 days after receiving second-line medical therapy, either infliximab or cyclosporine, at day 7 ( $n=29$ and 26), day 42 ( $n=29$ and 25 ), and day 98 ( $n=26$ and 24). Statistical significance was defined as $P<.005$ due to the numerous comparisons performed $(P$ value in bold).

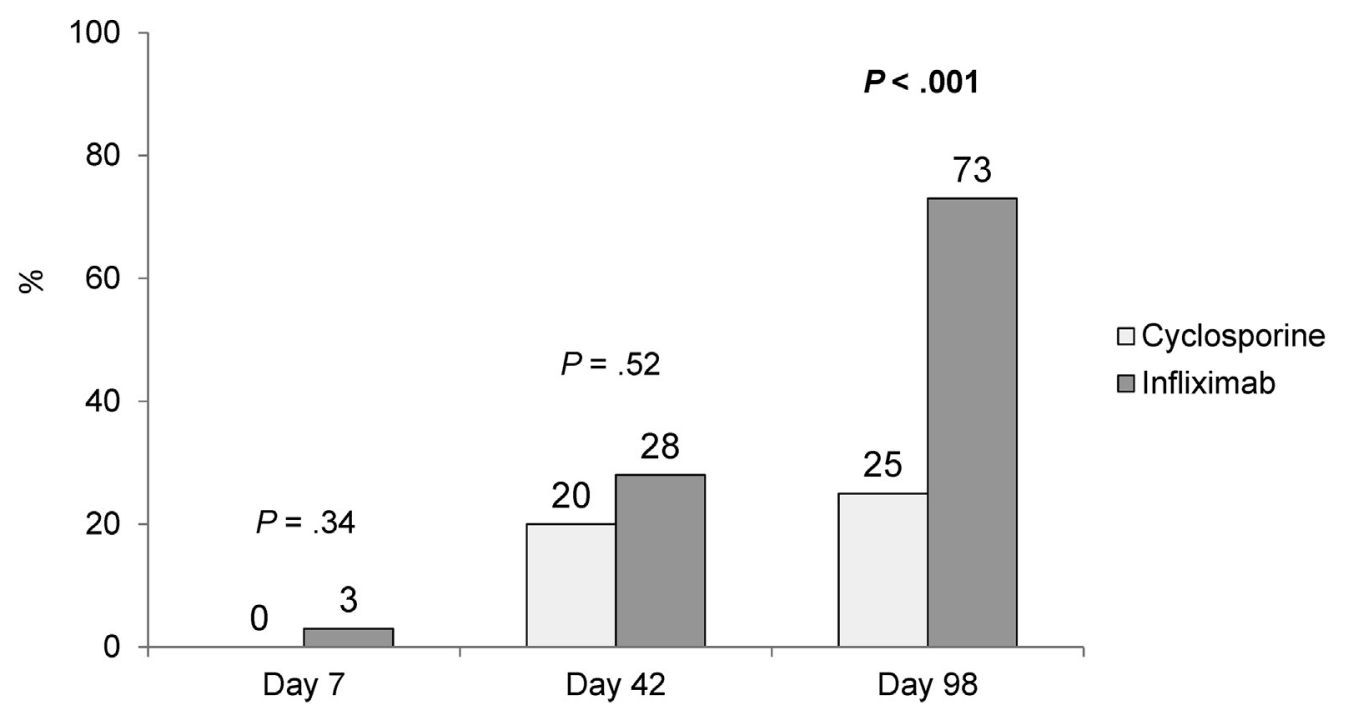


yet confirmed this relationship. Similar to Jarnerot et $\mathrm{al}^{26}$ who reported the first placebo-controlled trial conducted with infliximab in acute severe ulcerative colitis, baseline severe endoscopic lesions were not predictive of treatment failure in multivariate analysis in our trial. ${ }^{12}$ Moreover, we observed in the present study that patients with the UCEIS erosions or ulcerations subscore of 2 and 3 at inclusion have the same evolution for ulceration healing after day 7 , even if these results had to be taken with caution due to the evident lack of power. Overall, the significance of severe endoscopic lesions remains poorly understood and requires further studies.

The present study acknowledges some limitations such as UCEIS post hoc calculation, endoscopic assessments not centrally read and lack of histologic assessment. Last, as in most exploratory studies, numerous tests were performed. Nevertheless, we defined statistical significance as when the $P$ value was $<.005$.

In order to describe evolution of endoscopic lesions in patients responding to a second-line medical therapy, patients included into the present analysis were prospectively followed within a randomized clinical trial and closely monitored by 4 repeated flexible sigmoidoscopies using a standardized form describing prespecified endoscopic lesions per segment with few missing data.

In conclusion, endoscopic remission of acute severe ulcerative colitis takes approximately 3 months. It starts with bleeding remission at day 7 , followed by ulceration or erosion healing and then by restoration of the vascular pattern that is coming back to normal in half of patients at 3 months. In clinical practice, patients should not be assessed too early by flexible sigmoidoscopy. The higher rate of patients in endoscopic remission after induction with infliximab than cyclosporine may be associated with less subsequent disease flare, suggesting that deep remission would be a desirable goal in acute severe ulcerative colitis.

\section{Supplementary Material}

Note: To access the supplementary material accompanying this article, visit the online version of Clinical Gastroenterology and Hepatology at www.cghjournal.org, and at https://doi.org/10.1016/j.cgh.2020.08.001.

\section{References}

1. Ungaro R, Colombel JF, Lissoos T, et al. A treat-to-target update in ulcerative colitis: a systematic review. Am J Gastroenterol 2019;114:874-883.

2. Dinesen LC, Walsh AJ, Protic MN, et al. The pattern and outcome of acute severe colitis. J Crohns Colitis 2010;4:431-437.

3. Truelove SC, Witts LJ. Cortisone in ulcerative colitis; final report on a therapeutic trial. Br Med J 1955;2:1041-1048.

4. Harbord M, Eliakim R, Bettenworth D, et al. Third European Evidence-based Consensus on Diagnosis and Management of
Ulcerative Colitis. Part 2: Current Management. J Crohns Colitis 2017;11:769-784.

5. Dong C, Metzger M, Holsbø E, et al. Systematic review with meta-analysis: mortality in acute severe ulcerative colitis. Aliment Pharmacol Ther 2020;51:8-33.

6. Schroeder KW, Tremaine WJ, Ilstrup DM. Coated oral5aminosalicylic acid therapy for mildly to moderately active ulcerative colitis. A randomized study. N Engl J Med 1987; 317:1625-1629.

7. Travis SP, Schnell D, Krzeski P, et al. Developing an instrument to assess the endoscopic severity of ulcerative colitis: the UIcerative Colitis Endoscopic Index of Severity (UCEIS). Gut 2012; 61:535-542.

8. Travis SP, Schnell D, Krzeski P, et al. Reliability and initial validation of the ulcerative colitis endoscopic index of severity. Gastroenterology 2013;145:987-995.

9. Vuitton L, Peyrin-Biroulet L, Colombel JF, et al. Defining endoscopic response and remission in ulcerative colitis clinical trials: an international consensus Aliment. Pharmacol Ther 2017; 45:801-813.

10. Corte C, Fernandopulle N, Catuneanu AM, et al. Association between the ulcerative colitis endoscopic index of severity (UCEIS) and outcomes in acute severe ulcerative colitis. J Crohns Colitis 2015;9:376-381.

11. Xie T, Zhang T, Ding C, et al. Ulcerative Colitis Endoscopic Index of Severity (UCEIS) versus Mayo Endoscopic Score (MES) in guiding the need for colectomy in patients with acute severe colitis. Gastroenterol Rep 2018;6:38-44.

12. Laharie D, Bourreille A, Branche J, et al. Ciclosporine versus infliximab in acute severe colitis refractory to intravenous steroids: a randomized study. Lancet 2012;380:1909-1915.

13. Rutgeerts P, Sandborn WJ, Feagan BG, et al. Infliximab for induction and maintenance therapy for ulcerative colitis. N Engl J Med 2005;353:2462-2476.

14. Reinisch W, Sandborn WJ, Hommes DW, et al. Adalimumab for induction of clinical remission in moderately to severely active ulcerative colitis: results of a randomised controlled trial. Gut 2011;60:780-787.

15. Sandborn WJ, Feagan BG, Marano C, et al. Subcutaneous golimumab induces clinical response and remission in patients with moderate-to severe ulcerative colitis. Gastroenterology 2014;146:85-95.

16. Feagan BG, Rutgeerts $P$, Sands BE, et al. Vedolizumab as induction and maintenance therapy for ulcerative colitis. N Engl $J$ Med 2013;369:699-710.

17. Sandborn WJ, Su C, Sands BE, et al. Tofacitinib as induction and maintenance therapy for ulcerative colitis. N Engl J Med 2017;376:1723-1736.

18. Sands BE, Sandborn WJ, Panaccione R, et al. Ustekinumab as induction and maintenance therapy for ulcerative colitis. N Engl J Med 2019;381:1201-1214.

19. Sands BE, Peyrin-Biroulet L, Loftus EV Jr, et al. Vedolizumab versus adalimumab in moderate-to-severe ulcerative colitis. N Engl J Med 2019;381:1215-1226.

20. Laharie D, Bourreille A, Branche J, et al. Long-term outcome of patients with steroid-refractory acute severe UC treated with ciclosporin or infliximab. Gut 2018;67:237-243.

21. Williams JG, Alam MF, Alrubaiy L, et al. Comparison Of iNfliximab and ciclosporin in STeroid Resistant Ulcerative Colitis: pragmatic randomised Trial and economic evaluation (CONSTRUCT). Health Technol Assess 2016;20:1-320. 
22. Colombel JF, Rutgeerts P, Reinisch W, et al. Early mucosal healing with infliximab is associated with improved long-term clinical outcomes in ulcerative colitis. Gastroenterology 2011; 141:1194-1201.

23. Ardizzone S, Cassinotti A, Duca P, et al. Mucosal healing predicts late outcomes after the first course of corticosteroids for newly diagnosed ulcerative colitis. Clin Gastroenterol Hepatol 2011;9:483-489.

24. Barreiro-de Acosta M, Vallejo N, de la Iglesia D, et al. Evaluation of the risk of relapse in ulcerative colitis according to the degree of mucosal healing (Mayo 0 vs 1): a longitudinal cohort study. J Crohns Colitis 2016;10:13-19.

25. Carbonnel F, Lavergne A, Lémann M, et al. Colonoscopy of acute colitis. A safe and reliable tool for assessment of severity. Dig Dis Sci 1994;39:1550-1557.

26. Jarnerot G, Hertervig E, Friis-Liby I, et al. Infliximab as rescue therapy in severe to moderately severe ulcerative colitis: a randomized, placebo-controlled study. Gastroenterology 2005; 128:1805-1811.

27. Cacheux W, Seksik P, Lemann M, et al. Predictive factors of response to cyclosporine in steroid-refractory ulcerative colitis. Am J Gastroenterol 2008;103:637-642.

28. Monterubbianesi R, Aratari A, Armuzzi A, et al. Infliximab threedose induction regimen in severe corticosteroid-refractory ulcerative colitis: early and late outcome and predictors of colectomy. J Crohns Colitis 2014;8:852-858.

29. Poullenot F, Nivet D, Paul S, et al. Severe endoscopic lesions are not associated with more infliximab fecal loss in acute severe ulcerative colitis. Dig Liver Dis 2018;50:1100-1103.

30. Brandse JF, van den Brink GR, Wildenberg ME, et al. Loss of infliximab into feces is associated with lack of response to therapy in patients with severe ulcerative colitis. Gastroenterology 2015;149:350-355.

\section{Reprint requests}

Address requests for reprints to: David Laharie, MD, PhD, service d'Hépatogastroentérologie, Hôpital Haut-Lévêque, CHU de Bordeaux, 33600 Pessac, Francee-mail: david.laharie@chu-bordeaux.fr; fax: +33 557656445.

\section{Conflicts of interest}

These authors disclose the following: David Laharie declares counseling, boards, transports, or fees from AbbVie, Biogaran, Biogen, Ferring, HACpharma, Janssen, MSD, Novartis, Pfizer, Prometheus, Roche, Takeda, Theradiag, and Tillots. Arnaud Bourreille declares counseling, boards, transports, or fees from AbbVie, Ferring, Janssen, MSD, Novartis, Pfizer, Takeda, and Tillots. Julien Branche declares fees from AbbVie, Cook Medical, Boston Scientific,
MSD, and Mayoly Spindler. Matthieu Allez declares counseling, boards or fees from Amgen, Biogen, Celgene, Ferring, Genentech/Roche, Janssen, MSD, Novartis, Pfizer, Takeda, and Tillots. Yoram Bouhnik has received lecture and consulting fees from AbbVie, Biogaran, Boehringer-Ingelheim, CTMA, Ferring, Gilead, Hospira, ICON, Inception IBD, Janssen, Lilly, Mayoly Spindler, Merck, MSD, Norgine, Pfizer, Robarts Clinical Trials, Roche, Sanofi, Shire, Takeda UCB, and Vifor Pharma; and also owns stock in Inception IBD. Jerome Filippi declares lecture and consulting fees from AbbVie, Astellas pharma, Covidien, Ferring, Jansen, MSD, Pfizer, and Takeda. Frank Zerbib declares counseling, boards, transports, or fees from AbbVie, Allergan Reckitt Benckiser, Coloplast, Vifor Pharma, Takeda, Alfasigma, Janssen, Biocodex, Mayoly Spindler, and Ipsen. Guillaume Savoye declares boards, transports and fees from Ferring, Janssen, Mayoly Spindler, MSD, Pfizer, Takeda, Tillots, and Vifor Pharma. Lucine Vuitton declares lecture or consulting fees from AbbVie, Amgen, Gilead Ferring, Janssen, Mayoly, MSD, Takeda, and Pfizer. Aurelien Amiot declares consulting fees from AbbVie, Hospira, Janssen, Tillotts, Pfizer, Takeda, Gilead, and Biocodex; lecture fees and travel accommodations from AbbVie, Janssen, Biocodex, Hospira, Ferring, Pfizer, Ferring, Tillotts, Grifols, Takeda, and MSD advisory board fees from Gilead, Takeda, and AbbVie. Laurent Beaugerie received consulting fees from Janssen, Pfizer, and Takeda; lecture fees from AbbVie, Janssen, MSD, Ferring Pharmaceuticals, Mayoly Spindler, and Takeda; and research support from Abbott, Ferring Pharmaceuticals, HospiraPfizer, Janssen, MSD, Takeda, and Tillots. Elena Ricart declares lecture and consulting fees from MSD, AbbVie, Takeda, Janssen, Pfizer, Ferring, Amgen, and Fresenius-Kabi. O. Dewit declares lecture and consultant fees from AbbVie, Ferring, Fresenius-Kabi, Janssen, Mylan, MSD, Pfizer, and Takeda. Antonio Lopez-Sanroman declares lecture fees, consultant fees, or both from AbbVie, Ferring, MSD, Janssen, Takeda, Pfizer, Tillots, and Lilly; and research grant support from AbbVie and MSD. Mathurin Fumery declares lecture fees and consultant fees from AbbVie, Ferring, MSD, Janssen, Takeda, Gilead, Celgene, Boehringer, Pfizer, and Tillots. Anthony Buisson declares consulting fees for AbbVie, Amgen, Biogen, Janssen, MSD, Pfizer, Roche, Takeda, and Tillots; and lecture fees for AbbVie, Amgen, Biogen, Janssen, Mayoly-Spindler, MSD, Norgine Pfizer, Roche, Takeda, and Tillots. Benoit Coffin declares fees from AbbVie and Mayoly. Xavier Roblin declares fees from MSD, AbbVie, Celltrion, Janssen, Takeda, Amgen, and Pfizer. G. van Assche declares no conflict of interest in the last 18 months; since 2018 fees from AbbVie, Pfizer, Janssen, Takeda, Roche, MSD, and Ferring. Maria Esteve declares lecture fees and consultant fees from AbbVie, MSD, Janssen, Takeda, Pfizer, and Tillots; and has received research funding from MSD and AbbVie. Martti Farkkila declares lecture or consultation fees from AbbVie, Tillotts Pharma, DelSiTech, and Pfizer. J.P. Gisbert has served as a speaker, consultant, and advisory board member for or has received research funding from MSD, AbbVie, Hospira, Pfizer, Kern Pharma, Biogen, Takeda, Janssen, Roche, Sandoz, Celgene, Ferring, Faes Farma, Shire Pharmaceuticals, Dr. Falk Pharma, Tillotts Pharma, Chiesi, Casen Fleet, Gebro Pharma, Otsuka Pharmaceutical, and Vifor Pharma. Philippe Marteau declares fees from Biocodex, Ferring, Janssen, and Mayoly Spindler. Stephane Nahon declares lectures or advisory board fees from AbbVie, MSD, Vifor Pharma, Pfizer, Janssen, and Ferring. Laurent PeyrinBiroulet reports personal fees from AbbVie, Janssen, Genentech, Ferring, Tillots, Pharmacosmos, Celltrion, Takeda, Boehringer Ingelheim, Pfizer, Index Pharmaceuticals, Sandoz, Celgene, Biogen, Samsung Bioepis, Alma, Sterna, Nestle, Enterome, Allergan, MSD, Roche, Arena, Gilead, Hikma, Amgen, BMS, Vifor, Norgine, Mylan, Lilly, Fresenius Kabi, Oppilan Pharma, Sublimity Therapeutics, Applied Molecular Transport, OSE Immunotherapeutics, Enthera, and Theravance; reports grants from AbbVie, MSD, and Takeda; and own stock options in CTMA. The remaining authors disclose no conflicts.

\section{Funding}

This study was funded by the Association Francois Aupetit. 


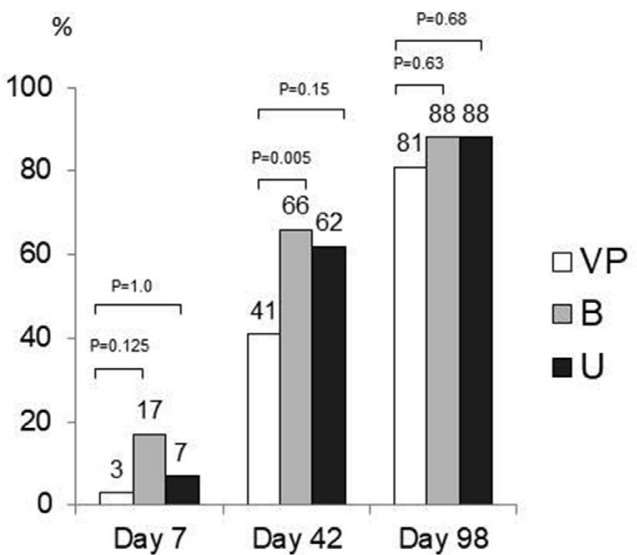

Infliximab

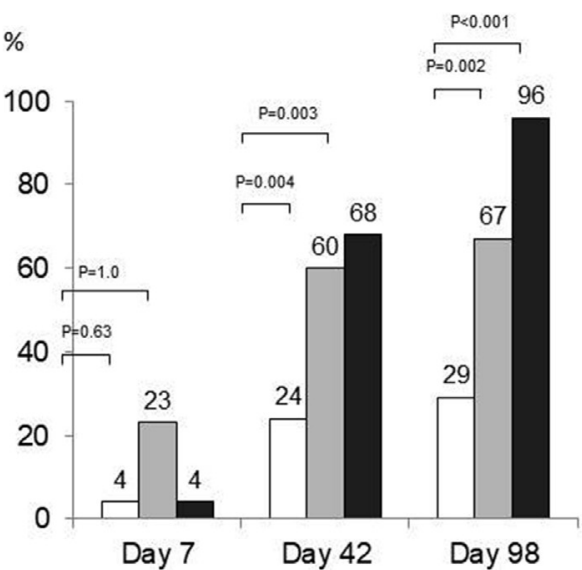

Cyclosporine

\section{Supplementary}

Figure 1. Rates of Ulcerative Colitis Endoscopic Index of Severity (UCEIS) subscores 0 in patients admitted for a steroidrefractory acute severe ulcerative colitis who achieved clinical remission 98 days according to treatment (infliximab or cyclosporine), at day 7 ( $n=29$ and 26$)$, day $42(n=29$ and $25)$, and day $98(\mathrm{n}=26$ and 24). B, bleeding, U, erosions or ulcerations; VP, vascular pattern.

\section{Cyclosporine}
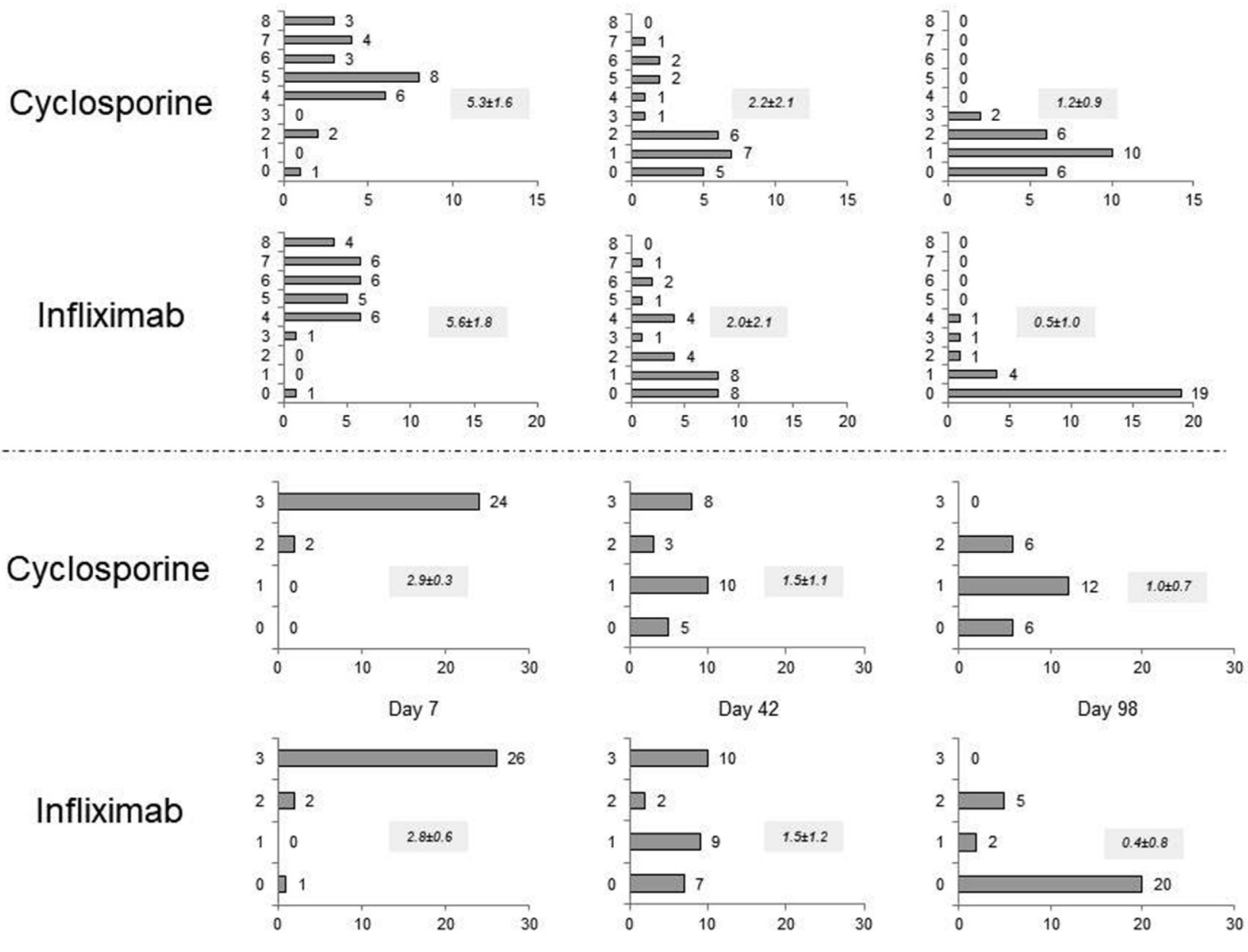

Day 7

Day 42

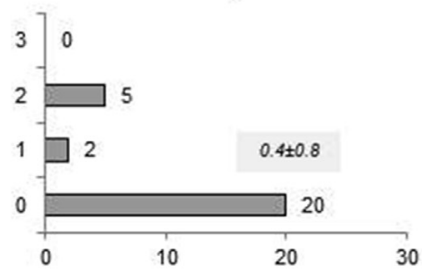

Day 98

Supplementary Figure 2. Description of the UCEIS scores (top) and Mayo endoscopic subscores (bottom) at days 0 ( $\mathrm{n}=55$ ), $7(n=55), 42(n=54)$, and $98(n=50)$ according to medication in patients admitted for a steroid-refractory acute severe ulcerative colitis who achieved clinical remission 98 days after receiving second-line medical therapy: number of patients for each level and mean \pm SD. 


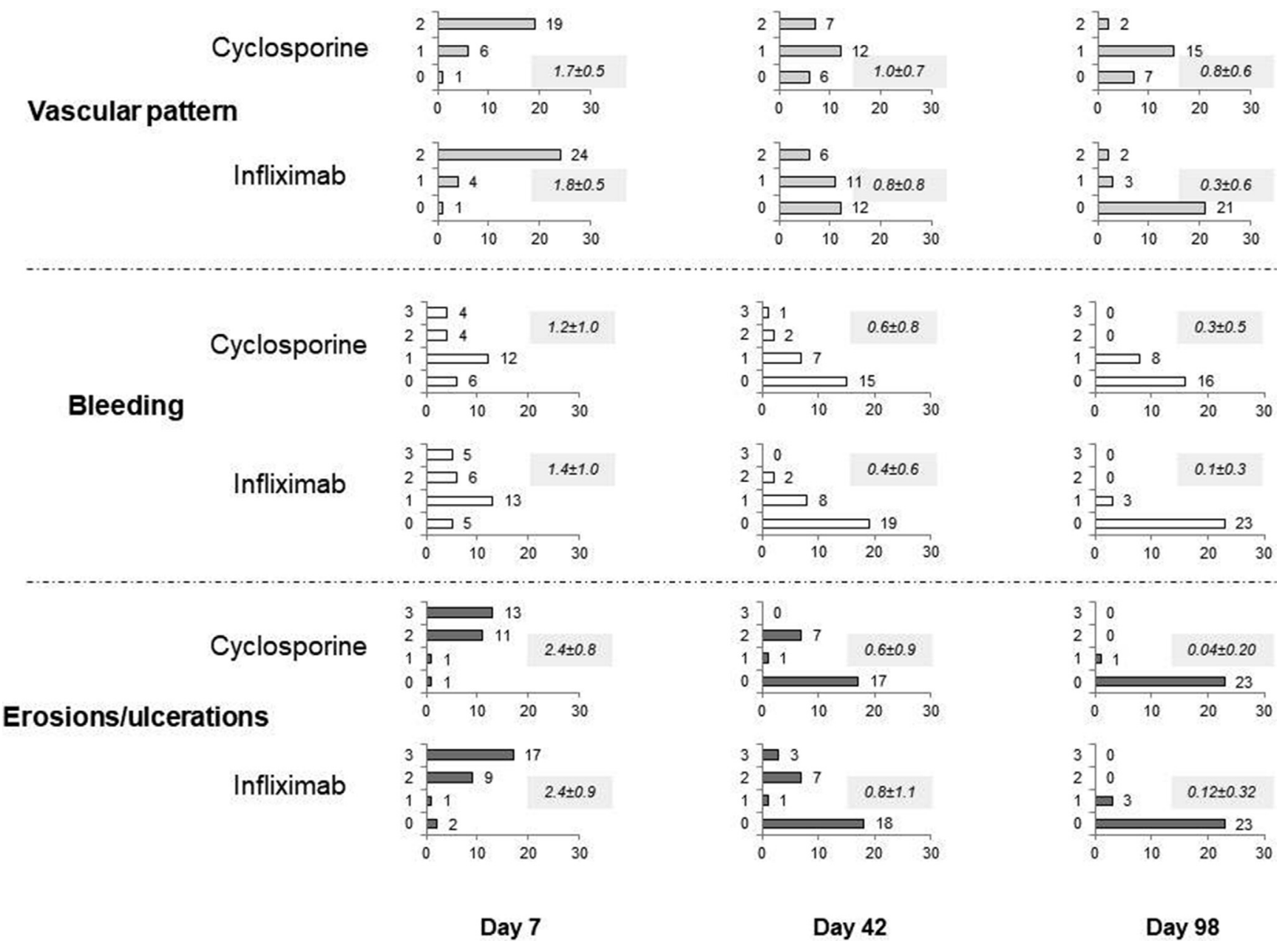

Supplementary Figure 3. Description of the UCEIS subscores at days $0(n=55), 7(n=55), 42(n=54)$ and $98(n=50)$ according to medication in patients admitted for a steroid-refractory acute severe ulcerative colitis who achieved clinical remission 98 days after receiving second-line medical therapy: number of patients for each level and mean \pm SD. 


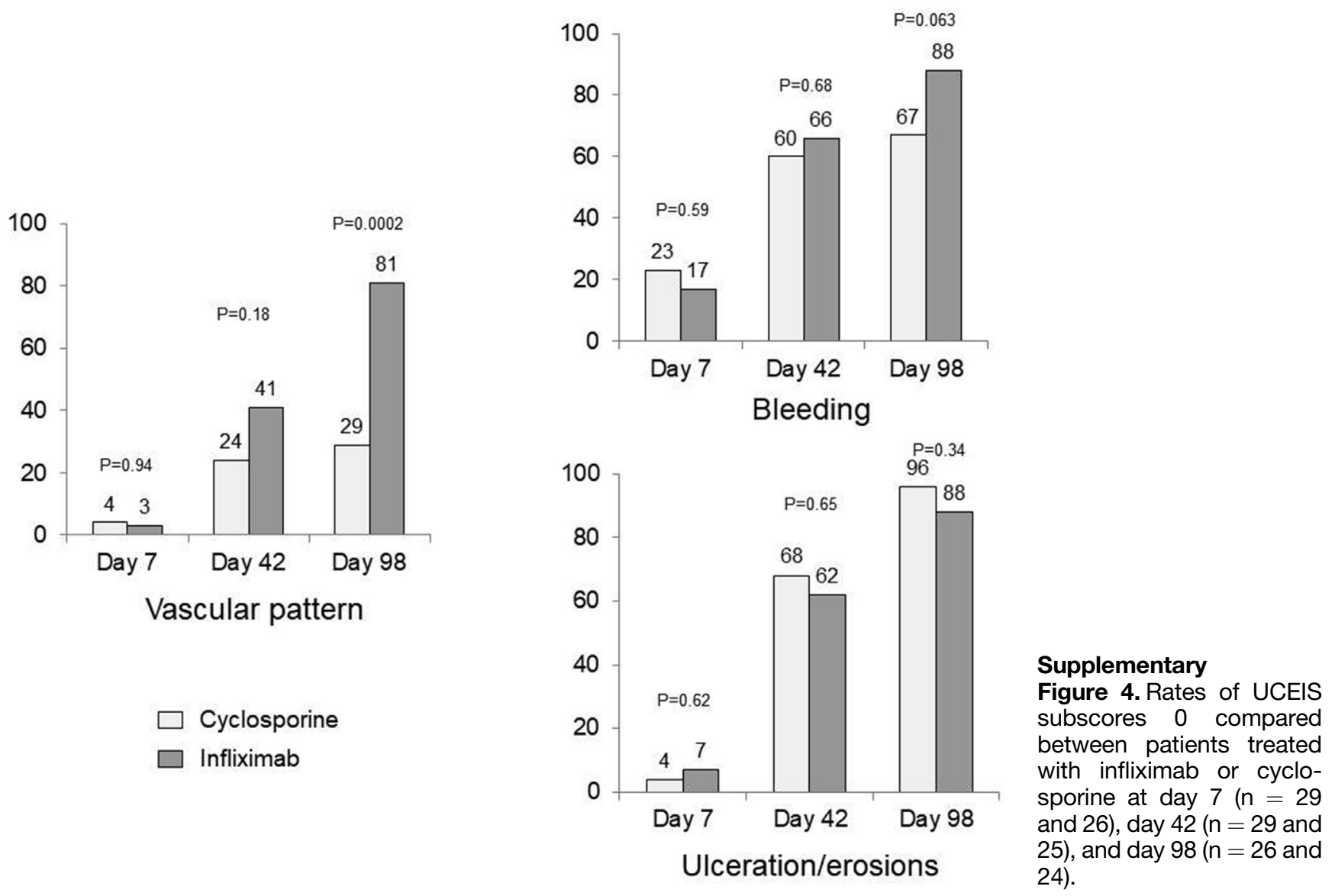

Supplementary Table 1. Global and Partial Endoscopic Remission Rates at Days 7, 42, and 98 in the Whole Population $(\mathrm{N}=55)$ According to Bowel Segment

\begin{tabular}{lccc}
\hline & Rectum & Sigmoid & $P$ Value \\
\hline Day 7 & & & \\
UCEIS 0 $(\mathrm{n}=54)$ & $3(6)$ & $2(4)$ & 1.00 \\
Vascular pattern 0 $(\mathrm{n}=55)$ & $3(5)$ & $4(7)$ & 1.00 \\
Bleeding 0 $(\mathrm{n}=55)$ & $19(35)$ & $15(27)$ & .39 \\
Erosion/ulcerations 0 $(\mathrm{n}=54)$ & $12(22)$ & $5(9)$ & .065 \\
Day 42 & & & \\
UCEIS 0 $(\mathrm{n}=50)$ & $18(36)$ & $16(32)$ & .77 \\
Vascular pattern 0 $(\mathrm{n}=53)$ & $23(43)$ & $22(42)$ & 1.00 \\
Bleeding 0 $(\mathrm{n}=53)$ & $37(70)$ & $40(75)$ & .51 \\
Erosion/ulcerations 0 $(\mathrm{n}=50)$ & $37(74)$ & $33(66)$ & .22 \\
Day 98 & & & \\
UCEIS 0 $(\mathrm{n}=47)$ & $27(57)$ & $34(72)$ & .092 \\
Vascular pattern 0 $(\mathrm{n}=50)$ & $31(62)$ & $38(76)$ & .092 \\
Bleeding 0 $(\mathrm{n}=50)$ & $41(82)$ & $41(82)$ & 1.00 \\
Erosion/ulcerations 0 $(\mathrm{n}=47)$ & $43(91)$ & $45(96)$ & .50 \\
& & & \\
\hline
\end{tabular}

UCEIS, Ulcerative Colitis Endoscopic Index of Severity. 
Supplementary Table 2. Median Rectal Bleeding and Stool Frequency Scores and CRP Levels at day 7, 42, and 98 Among the 55 Patients Who Responded to Infliximab or Cyclosporine After Intravenous Steroid Failure

\begin{tabular}{|c|c|c|c|}
\hline & Infliximab (n = 29) & Cyclosporine $(\mathrm{n}=26)$ & $P$ Value \\
\hline \multicolumn{4}{|c|}{ Rectal bleeding score } \\
\hline Baseline & $2.3 \pm 0.8$ & $2.8 \pm 0.9$ & .75 \\
\hline Day 7 & $0.3 \pm 0.7$ & $0.7 \pm 0.9$ & .07 \\
\hline Day 42 & $0.1 \pm 0.4$ & $0.2 \pm 0.6$ & .55 \\
\hline Day 98 & 0.0 & $0.1 \pm 0.3$ & .06 \\
\hline \multicolumn{4}{|c|}{ Stool frequency score } \\
\hline Baseline & $2.9 \pm 0.3$ & $2.6 \pm 0.6$ & .05 \\
\hline Day 7 & $1.1 \pm 0.9$ & $1.0 \pm 0.8$ & .81 \\
\hline Day 42 & $0.3 \pm 0.7$ & $0.2 \pm 0.4$ & .82 \\
\hline Day 98 & $0.2 \pm 0.4$ & $0.1 \pm 0.3$ & .55 \\
\hline \multicolumn{4}{|l|}{ CRP level } \\
\hline Baseline & $46(31-73)$ & $28(18-50)$ & .05 \\
\hline Day 7 & $4(3-17)$ & $8(4-19)$ & .33 \\
\hline Day 42 & $2.5(1-7)$ & $2.5(1-4)$ & .70 \\
\hline Day 98 & $2.5(1-5)$ & $2.5(1-4)$ & .58 \\
\hline
\end{tabular}

NOTE. Values are mean $\pm S D$ or median (interquartile range).

CRP, C-reactive protein. 